\title{
Towards Land Surface Model Validation from Using Satellite Retrieved Soil Moisture
}

\author{
M. Yee, J. P. Walker, G. Dumedah, A. Monerris and C. Rüdiger \\ Department of Civil Engineering, Monash University, Clayton, Australia \\ Email:
}

\begin{abstract}
Land surface model validation at distributed scales is important for model improvements. Recent advances in satellite technology provide an opportunity for distributed calibration and validation of land surface models. In the past years, a number of active and passive microwave soil moisture products have become available. While passive microwave soil moisture is the preferred approach for soil moisture observation, its disadvantage is the coarse spatial resolution it affords. Moreover, many of the available satellites use sub-optimal wavelengths, and the satellite retrieval algorithms are still under development. Consequently, the accuracy of these satellite data sets needs to be verified prior to their application. However, the spatial and temporal discrepancies between in-situ monitoring and satellite footprint retrievals continue to make absolute verification of satellite retrieved soil moisture a difficult problem.
\end{abstract}

The Advanced Microwave Scanning Radiometer-2 (AMSR-2) onboard the Global Change Observation Mission 1 - Water (GCOM-W1) was launched by JAXA in May 2012. AMSR-2 is a follow on of the AMSR-Earth Observing System (AMSR-E) onboard Aqua and of the AMSR onboard the Advanced Earth Observing Satellite 2 (ADEOS-II). By combining data from AMSR, AMSR-E and AMSR-2, a 20-year record of near-continuous C-band measurements of soil moisture content is expected to be available, starting from 2001.

This study makes an inter-comparison between in-situ data from the OzNet soil moisture network (www.oznet.org.au), the AMSR-2 soil moisture product, and simulated soil moisture using JULES (Joint UK Land Environment Simulator) for the period July to December 2012. The area selected is a $60 \mathrm{~km} \times 60 \mathrm{~km}$ study site in Yanco, NSW, Australia $\left(34.561^{\circ} \mathrm{S}, 35.170^{\circ} \mathrm{S}, 145.826^{\circ} \mathrm{E}, 146.439^{\circ} \mathrm{E}\right) .10 \mathrm{~km}$ and $25 \mathrm{~km}$ soil moisture products from the descending orbit of AMSR-2, which has a repeat time of 1 to 2 days, has been used. The JULES land surface model was run at hourly time-steps and approximately $1 \mathrm{~km}\left(0.01^{\circ}\right)$ resolution for the entire $60 \mathrm{~km} \times 60 \mathrm{~km}$ Yanco area, which coincides with twenty-five $10 \mathrm{~km}$ and four $25 \mathrm{~km}$ AMSR-2 product grids at hourly time-steps. Due to the co-location between in-situ monitoring stations and AMSR-2 grids, comparison between both data sets was only possible at five $10 \mathrm{~km}$ and two $25 \mathrm{~km}$ AMSR-2 pixels. Where in-situ stations are available, time series of AMSR-2 soil moisture and JULES simulations were validated against in-situ measurements. AMSR-2 products and JULES simulations were also compared against each other.

The average RMSD for both $10 \mathrm{~km}$ and $25 \mathrm{~km}$ products were found to be $0.05 \mathrm{~m}^{3} / \mathrm{m}^{3}$ when compared to insitu data, which meets the target accuracy of the mission. The AMSR-2 soil moisture was used to evaluate simulated soil moisture. Being a consistent product across time and space, AMSR-2 soil moisture can be used to identify where model simulations are inaccurate due to forcing data, parameter assignment or model physics. Whilst the opportunity in using AMSR-2 soil moisture to validate land surface models run at distributed scales was demonstrated, this study could not conclude whether the satellite or simulated soil moisture is more accurate due to possible inaccuracies in the current radiative transfer model, parameterization of soil and vegetation characteristics and prescription of precipitation data in the land surface model. The study also indicated prospects in further studies for better understanding of the Yanco site in relation to 1) representativeness of the sites used for validation and 2) effects caused by vegetation and standing water within the satellite footprint to improve the retrieval algorithm of AMSR-2 soil moisture for Australian conditions.

Keywords: Surface soil moisture; remote sensing; scaling; land surface model; AMSR-2 
Yee et al., Towards land surface model validation from using satellite retrieved soil moisture

\section{INTRODUCTION}

Land surface models simulate the exchange of mass and energy between the Earth's surface and the atmosphere mass and energy exchange between the Earth's surface processes and the atmosphere and are frequently validated against in-situ measurements of soil moisture, soil temperature, energy and water vapour fluxes, and/or stream discharge and remote sensing products (Chen et al., 1996; Grasselt et al., 2008; Loaiza Usuga et al., 2008; Blyth et al., 2009; Li et al., 2012). This has improved our understanding of the interactions between land surface processes at point scales (Beven, 1977). However, as land surface modeling has evolved from point scales to distributed scales, the applicability of point based calibration and validation to distributed scale applications has been debated (Beven, 1989; Bergström, 1991; Refsgaard, 1997). Moreover, the ability of models to simulate spatial patterns is highly dependent on the spatial availability of the meteorological data used to force the model, and the soil and vegetation parameters to prescribe the model. With soil moisture simulated by models widely acknowledged as being to be model dependent, there is an urgent need to calibrate and validate distributed models with spatially explicit data (Grayson et al., 2001).

Remote sensing observations provide an opportunity to validate distributed land surface model simulations. Passive microwave remote sensing of soil moisture has several advantages over other remote sensing methods due to its ability to penetrate cloud, and its lower sensitivity to vegetation cover and land surface roughness (Jackson, 1993). In May 2012, the GCOM-W1 satellite (Global Change Observation Mission 1 Water) was launched by the Japan Aerospace Exploration Agency (JAXA), carrying onboard the Advanced Microwave Scanning Radiometer-2 (AMSR-2). Whilst AMSR-2 has similar characteristics to AMSR-E, it carries a larger main reflector, which translates into an improved spatial resolution. It also has an additional dual polarized frequency at $7.3 \mathrm{GHz}$ (to identify radio-frequency interference, RFI) and an improved calibration system with respect to its predecessor (Imaoka et al., 2010). However, there is a need to validate the accuracy of the soil moisture obtained from AMSR-2 with in-situ soil moisture observations before they can be used to validate and/or calibrate land surface models. This paper aims to assess the applicability of 10 $\mathrm{km}$ and $25 \mathrm{~km}$ AMSR-2 soil moisture products (nominal resolution is $75 \mathrm{~km} \times 43 \mathrm{~km}$ ) to validate land surface model simulations at distributed scales. Consequently, the AMSR-2 soil moisture products are first validated using in-situ soil moisture observations from the OzNet monitoring network (www.oznet.org.asu) in the Yanco region of the Murrumbidgee River Catchment, southeast Australia, to characterize its errors and ability to capture the temporal and spatial variation of soil moisture in the study area. These AMSR-2 data were then used to validate simulations from the Joint UK Land and Environment Simulator (JULES), which was run across an area of approximately $60 \mathrm{~km} \times 60 \mathrm{~km}$ at $1 \mathrm{~km}$ resolution within the Yanco region.

\section{METHODS}

\subsection{The land surface model and input data sets}

The Joint UK Land and Environment Simulator (JULES) was used in this study to simulate soil moisture across the study site. JULES is a tiled (patched or mosaic) model of sub-grid heterogeneity, meaning that the area within a grid can be divided into patches of bare soil and vegetation, with fluxes at each patch modeled. Whilst JULES consists of four sub-models (soil, snow, vegetation and radiation), the focus in this paper is the soil sub-model, specifically the soil hydrology component for the simulation of soil moisture (Best et al., 2011).

The meteorological forcing data which is needed to run the model include downward long-wave and shortwave radiation, rainfall, zonal component of the wind $(\mathrm{u})$, meriodinal component of the wind (v), specific humidity, air pressure and air temperature. Additionally, the parameters and initial conditions of each soil grid and layer has to be specified.

Meteorological data used to run the model were obtained from the Australian Community Climate and EarthSystem Simulator (Australia) (ACCESS-A) (Jones et al., 2009; Raupach et al., 2009; Raupach et al., 2012) at hourly time-steps. ACCESS is the Australian operational Numerical Weather Prediction system, which provides meteorological data at a resolution of $\sim 12 \mathrm{~km}$. Whilst previous studies are unclear as to whether ACCESS has a tendency to over- or under-estimate precipitation, it is generally known that the forecasts are biased (BoM, 2010; Shahrban et al., 2011). Therefore, as precipitation is the most important forcing for soil moisture estimation, the hourly precipitation data from ACCESS was bias corrected based on the daily rainfall from the Australian Water Availability Project (AWAP). AWAP provides Australia wide daily 
precipitation on a $0.05^{\circ} \times 0.05^{\circ}(\sim 5 \mathrm{~km})$ grid from the spatial analysis of in-situ surface observations (Raupach, Briggs et al., 2009; Raupach, Briggs et al., 2012).

The correction and disaggregation of precipitation forcing is carried out in two main steps. Firstly, the $\sim 5 \mathrm{~km}$ AWAP grid is regridded to the $\sim 12 \mathrm{~km}$ ACCESS grid based on a weighted average of AWAP cell within an ACCESS cell. The ACCESS rainfall is biased corrected based on the re-gridded AWAP daily precipitation. Next, the corrected ACCESS rainfall is disaggregated to the JULES $1 \mathrm{~km}$ grid whereby the precipitation from the ACCESS cell with the largest area within the corresponding JULES cell is assigned.

Soil parameters used in this study were derived from the Digital Atlas of Australian Soils (McKenzie et al., 2000), and land cover was based on the national dynamic land cover dataset (Lymburner et al., 2011).

The model has been run from January 2010 to December 2012 at $1 \mathrm{~km}$ resolution with January 2010 to June 2012 taken as a pre-run and only the simulations after July 2012 used for analysis. A pre-run was carried out instead of the traditional spin-up method to initialize the model as recommended in Bandara et al. (2013).

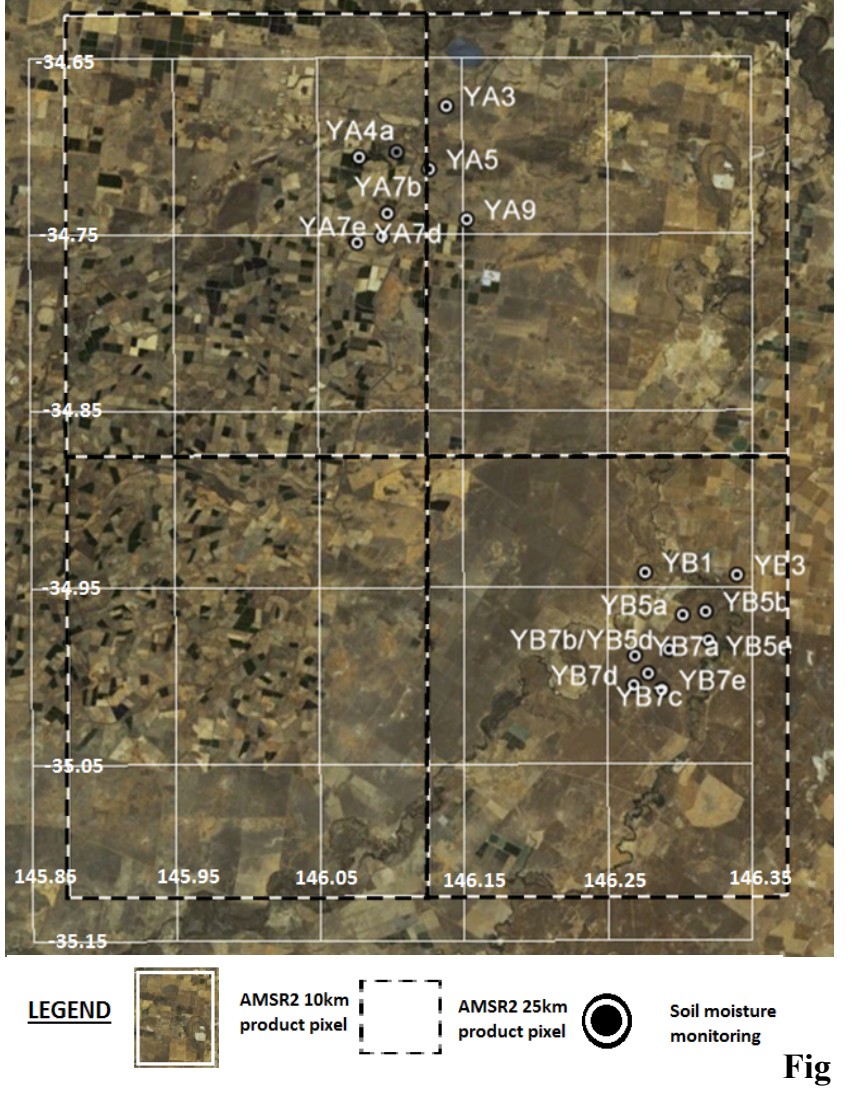

ure 1: Overview of the Yanco study area. The location of the OzNet in-situ monitoring stations as well as the AMSR-2 grids are shown.

\subsection{AMSR-2 soil moisture data}

A land soil moisture product is provided by JAXA every 1 to 2 days from both the ascending $(13: 30 \pm 15 \mathrm{~min}$ local time) and descending (01:30 $\pm 15 \mathrm{~min}$ local time) overpasses at $10 \mathrm{~km}$ and $25 \mathrm{~km}$ spatial scales, and available for download from https://gcom-w1.jaxa.jp/. Observations are available starting July 2012 and the product version 0.0 has been used in this study. Although soil moisture are provided for both ascending and descending overpasses, this study only uses descending passes due to the assumptions made in retrieval algorithms that the vegetation and near-surface soil temperature is the same.

\subsection{In-situ soil moisture data}

The in-situ soil moisture data were obtained from the Yanco area $34.561^{\circ} \mathrm{S}, 35.170^{\circ} \mathrm{S}, 145.826^{\circ} \mathrm{E}$, $146.439^{\circ} \mathrm{E}$ ), a $60 \mathrm{~km} \times 60 \mathrm{~km}$ intensive study area within the Murrumbidgee river catchment in NSW, Australia. This soil moisture monitoring network (OzNet) has been recording soil moisture data since 2001 (www.oznet.org.au, Smith et al. 2012). The Yanco area is generally flat with irrigation and cropping areas predominantly in the north (YA area) and pastures predominantly in the south (YB area) - see Figure 1. The soil type is mainly sandy and silty loams.

This area has been extensively monitored and a series of field experiments have been performed in the past to contribute to the pre- and post-launch algorithm development of missions such as SMOS (National Airborne Field Experiment 2006, Merlin et al. 2008; Australian Airborne cal/val Experiments for SMOS, Peischl et al., 2012). The site has also been selected for calibration/validation of the NASA SMAP mission, and long-term field experiments have been recently conducted (Soil Moisture Active Passive Experiments, Panciera et al., 2013).

Out of 37 soil moisture monitoring stations within the study area, only 18 stations have been used in this analysis due to availability of processed data at the time when this study was carried out. These stations fall within five AMSR-2 $10 \mathrm{~km}$ product grids and three AMSR-2 $25 \mathrm{~km}$ products grids (see Figure 1). In-situ soil moisture measurements are recorded every 2 hours. The near-surface soil measurements $(0-5 \mathrm{~cm})$ from 
Stevens Water Hydraprobes which has an accuracy of $0.03 \mathrm{~m}^{3} / \mathrm{m}^{3}$ (Merlin et al., 2007) have been used as satellite observations at C-band correspond to a shallow sensing depth of just a few centimeters. Comparisons were carried out for observations from July to December 2012. As night time (descending) observations by AMSR-2 occur between approximately 1.30am and 2.30am local time (AEST), observations and simulations were sub-sampled at $2 \mathrm{am}$ for comparison.

\section{VALIDATION}

\subsection{Comparison of AMSR-2 and JULES soil moisture against OzNet in-situ data}

The AMSR-2 and JULES soil moisture data are evaluated against in-situ soil moisture observations from July to December 2012 (Figure 2). In addition to the 10 $\mathrm{km}$ and $25 \mathrm{~km}$ products provided by JAXA, assessments were also carried out for an assumed $50 \mathrm{~km}$ product
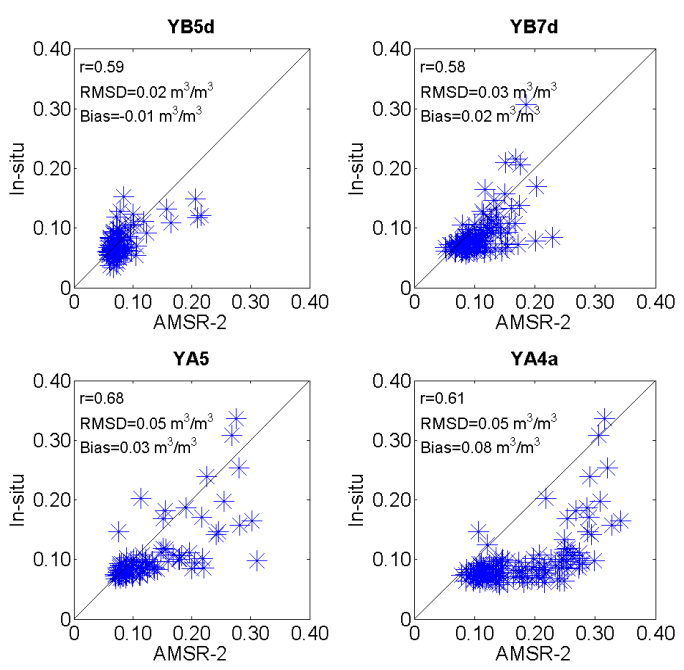

Figure 2: Comparison of top $5 \mathrm{~cm}$ in-situ soil moisture measurements at individual stations and AMSR-2 $10 \mathrm{~km}$ soil moisture sharing the same pixel center as the $10 \mathrm{~km}$ product as the actual footprint area observed by the microwave sensor is approximately $75 \mathrm{~km} \times 43 \mathrm{~km}$.

The same analysis was carried out comparing in-situ observations, land surface model simulations and AMSR-2 soil moisture (Figure 3). All the observations or simulations which fall within a given satellite pixel are averaged to obtain a pixel value at $10 \mathrm{~km}, 25 \mathrm{~km}$ and $50 \mathrm{~km}$. The comparison of average soil moisture obtained from the stations (the first an average of all available stations and the second being the average of pre-selected stations), AMSR-2 and JULES for two AMSR-2 pixels at $10 \mathrm{~km}$ and $25 \mathrm{~km}$.

\subsection{Validation of the land surface model}

With a better understanding of the accuracy of the AMSR-2 soil moisture, the land surface model was validated using the AMSR-2 soil moisture. Given the high spatial resolution of model predictions, the simulated pixels that fall within the same satellite product pixels were averaged to obtain a single value at 10 $\mathrm{km}, 25 \mathrm{~km}$ and $50 \mathrm{~km}$ scales, at 2 am AEST for each day.

A spatial representation of the soil moisture simulated by JULES in comparison to the AMSR-2 $10 \mathrm{~km}$ soil moisture product on the 18th of August 2012 at 2am is shown in Figure 4. The ability of the land surface model to simulate the spatial and temporal variability of soil moisture for the study area is further assessed by computing the same suite of statistical parameters as before on a pixel by pixel basis, spatially depicted in Figure 5.

\section{RESULTS AND DISCUSSION}

\subsection{AMSR-2 Validation}

The average RMSD for both $10 \mathrm{~km}$ and $25 \mathrm{~km}$ products were found to be $0.05 \mathrm{~m}^{3} / \mathrm{m}^{3}$, meeting the target accuracy of the mission. The correlations with in-situ measurements were 0.56 and 0.51 . This is consistent with the findings from validation activities by JAXA (EORC, 2013). However, the curve under the xy-line that can be seen in the scatterplots (Figure 2) may be caused by a problem in the retrieval algorithm used to derive the AMSR-2 soil moisture. Rasmy (2013) has also found that the descending soil moisture from AMSR-2 in Yanco does not correspond well with the retrieved brightness temperatures, thereby suggesting the retrieval algorithm needs to be further refined. Furthermore, initial validation based on averaging all the available stations showed peaks which were not detected by AMSR-2. Further investigation identified two stations (YA4b and YA7b) which did not show the same temporal dynamics as the rest of the stations. Based on temporal stability analysis, Disseldorp (2013) also found that YA4b and YA7b were the least representative of the YA area. Consequently, an average of soil moisture without these two stations was computed and also plotted in Figure 3. Based on these comparisons, the importance of careful selection of 
representative sites prior to using averages of point measurements for the validation of satellite products is emphasized.

An inter-comparison between the $10 \mathrm{~km}, 25 \mathrm{~km}$, and assumed $50 \mathrm{~km}$ AMSR-2 soil moisture also showed that the average RMSD for the $50 \mathrm{~km}$ product $\left(0.04 \mathrm{~m}^{3} / \mathrm{m}^{3}\right)$ was lower than that of the $10 \mathrm{~km}$ and $25 \mathrm{~km}$ (both $0.05 \mathrm{~m}^{3} / \mathrm{m}^{3}$ ) soil moisture product. Remotely-sensed soil moisture is derived based on brightness temperatures sensed for a larger footprint that the scale of the retrieved soil moisture products. Also, the center point of the satellite footprint is not always constant with each overpass. In a homogeneous landscape, this is not an issue but for an area such as Yanco whereby within a single footprint, irrigation activities, trees and standing water are present, non-linearities in radiative transfer processes will mean that the retrieved soil moisture may not represent an area average of soil moisture unless specifically taken into account (Panciera et al., 2011).

\subsection{Land surface model validation}

The land surface model is first validated at the point-scales where in-situ measurements are available (Figure 3). In comparison to in-situ measurements, the mean RMSD, $\mathrm{r}$ and bias for $10 \mathrm{~km}$ products were $0.03 \mathrm{~m}^{3} / \mathrm{m}^{3}$, 0.74 and $0.01 \mathrm{~m}^{3} / \mathrm{m}^{3}$, and for $25 \mathrm{~km}$ products, $0.04 \mathrm{~m}^{3} / \mathrm{m}^{3}, 0.62$ and $0.01 \mathrm{~m}^{3} / \mathrm{m}^{3}$. Whilst the dynamics of the
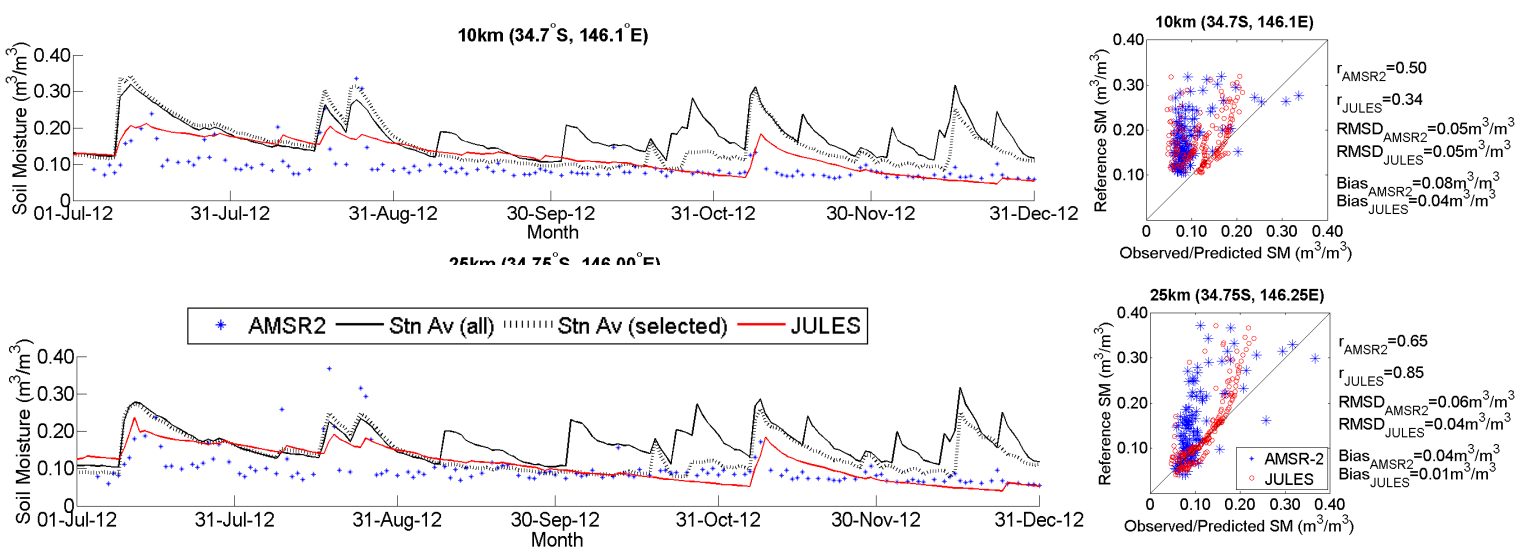

Figure 3: Soil moisture time-series and associated scatterplots of average in-situ soil moisture (reference), AMSR-2 soil moisture and simulated soil moisture in the top $5 \mathrm{~cm}$ at $10 \mathrm{~km}$ and $25 \mathrm{~km}$ (coordinates of product mid-point shown in parentheses).

soil moisture is well captured it is noticed that this is only when the forcing data fed to the model is accurate. There are instances (October) where soil moisture variation was detected by in-situ stations or AMSR-2 but not simulated in JULES. This likely to be caused by the bias correction scheme which assumes that there is no precipitation when no rain is predicted on either the AWAP or ACCESS data.

The spatial distribution of soil moisture estimate by JULES was also carried out both qualitatively (Figure 4) and quantitatively (Figure 5). Comparisons for the $18^{\text {th }}$ of August are taken as an example. Retrievals from AMSR-2 show higher variability in soil moisture (rain was recorded on this day), and thus the pattern between the observed (AMSR-2) and simulated (JULES) was found to be different (Figure 4). Whilst the earlier assessment showed that JULES could simulate nearsurface soil moisture reasonably well
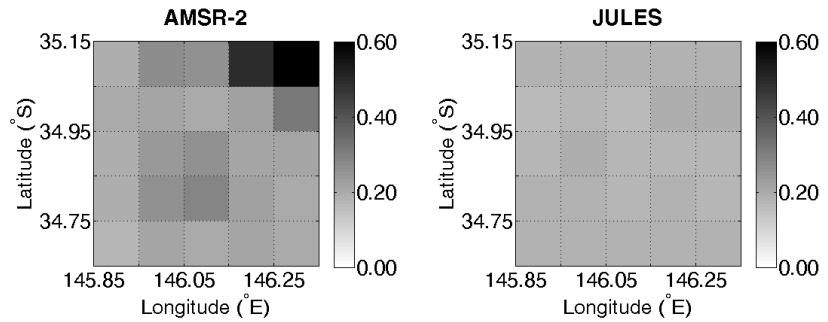

Figure 4: Spatial plot of top $5 \mathrm{~cm}$ AMSR-2 $10 \mathrm{~km}$ product and JULES simulated soil moisture at $2 \mathrm{am}$ on 18/08/2012.
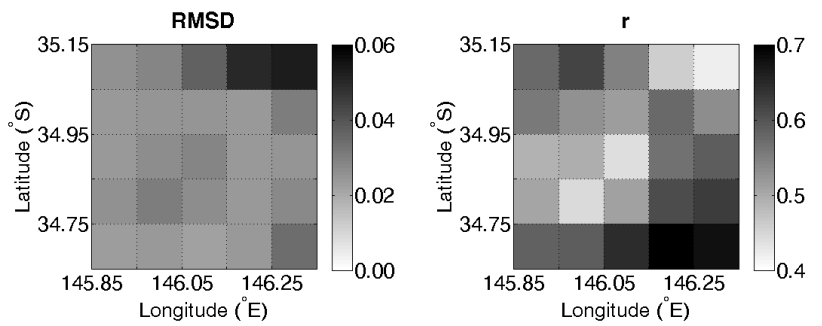

Figure 5: Spatial plot of RMSD and $r$ between JULES simulated and AMSR-2 retrieved $10 \mathrm{~km}$ product of top $5 \mathrm{~cm}$ soil moisture. 
Yee et al., Towards land surface model validation from using satellite retrieved soil moisture

at point scale, this spatial assessment indicated otherwise, especially considering that the variation in the magnitude of AMSR-2 soil moisture is smaller than the model at a point scale.

Comparisons between AMSR-2 and JULES shows RMSD is above $0.05 \mathrm{~m}^{3} / \mathrm{m}^{3}$ and $\mathrm{r}$ is below 0.5 for the two cells located at the north-eastern corner of the study area where trees and water bodies are present. Also, where agriculture exists on the western side, $r$ between JULES simulations and AMSR-2 soil moisture are lower and RMSD is higher. The presence of standing water and vegetation would have affected the AMSR-2 retrievals.

The overall mean and standard deviation for all three datasets were $0.06 \mathrm{~m}^{3} / \mathrm{m}^{3}$ and $0.01 \mathrm{~m}^{3} / \mathrm{m}^{3}$ respectively. Whilst RMSD may seem insignificant, as a percentage of mean in-situ measurements the RMSD for AMSR2 and JULES simulations at $10 \mathrm{~km}$ and $25 \mathrm{~km}$ are $37 \%, 35 \%, 25 \%$ and $27 \%$. Based on these observations, it cannot be concluded whether the satellite or simulated soil moisture is more accurate at this point of time as the discrepancy in pattern can be caused by 1) inaccurate retrievals caused by the current radiative transfer model and its representation of vegetation and standing water, 2) inaccurate parameterization of soil and vegetation characteristics in land surface model due to lack of information at finer scales, or 3 ) inaccurate prescription of precipitation data.

\section{CONCLUSION}

The utility of the AMSR-2 soil moisture in validating land surface models run at distributed scales was demonstrated in this study. First, the derived soil moisture was compared with soil moisture measured at insitu monitoring stations to determine the ability of the satellite product to represent a $10 \mathrm{~km}$ or $25 \mathrm{~km}$ grid. The AMSR-2 soil moisture were then used to validate simulations from the JULES model run at $1 \mathrm{~km}$ resolution for the $60 \mathrm{~km} \times 60 \mathrm{~km}$ study area. Though results generally show a significant correlation between in-situ measurements, AMSR-2 soil moisture products and model simulations, there is room for improvement. To date, the preferred method for evaluating land surface models are still based on dense networks of in-situ measurements. However, as the availability of a dense soil moisture monitoring network outside of experimental test beds such as this is limited, validation of soil moisture simulations by land surface models at distributed scales are even more complicated. Consequently, remote sensing yields an opportunity to provide consistent soil moisture retrievals in time and space. However, before satellite products can be used to validate these models, results indicate the need for more improvement. In particular, there is a need for better understanding of the Yanco site in relation to 1) representativeness of the sites used for validation, 2) effects caused by vegetation and standing water within the satellite footprint to improve the retrieval algorithm of AMSR-2 soil moisture for Australian conditions. Moreover, with the improvement of soil moisture measurements using space borne sensors (e.g. SMAP which operates at L-band and has a deeper observation depth than C-band sensors), it is anticipated that global land surface models can be evaluated to identify errors in parameterization of soil and vegetation characteristics and forcing data, and the model's physics can be refined to better reflect measurements.

\section{ACKNOWLEDGMENTS}

This study was made possible through the provision of Earth Observation Satellite Data by JAXA (Specification no.: JX-PSPC-349279, Contract No.: 11RS-01707), and funding for the monitoring network by DP0984586 projects from the ARC. The initial setup and maintenance of the study area were funded by earlier ARC grants (DP0343778, DP0557543, DP0879272), and the CRC for Catchment Hydrology.

\section{REFERENCES}

Bandara, R., J. P. Walker and C. Rüdiger (2013). Land Surface Model Initialization: A Comparison of 'prerun' and 'spin-up' (Manuscript in preparation), Monash University.

Bergström, S. (1991). Principles and confidence in hydrological modelling. Nord. Hydrol. 22(2): 123-136.

Best, M., M. Pryor, D. Clark, G. Rooney, R. Essery, C. Ménard, J. Edwards, M. Hendry, A. Porson and N. Gedney (2011). The Joint UK Land Environment Simulator (JULES), model description-Part 1: energy and water fluxes. Geoscientific Model Development 4(3): 677-699.

Beven, K. (1977). Hillslope hydrographs by the finite element method. Earth Surface Processes 2(1): 13-28.

Beven, K. (1989). Changing ideas in hydrology — The case of physically-based models. Journal of Hydrology 105(1-2): 157-172.

Blyth, E., J. Gash, A. Lloyd, M. Pryor, G. P. Weedon and J. Shuttleworth (2009). Evaluating the JULES Land Surface Model Energy Fluxes Using FLUXNET Data. Journal of Hydrometeorology 11(2): 509-519. 
Yee et al., Towards land surface model validation from using satellite retrieved soil moisture

BoM (2010). Operational implementation of the ACCESS Numerical Weather Prediction systems. NMOC Operations Bulletin. 83.

Chen, F., K. Mitchell, J. Schaake, Y. Xue, H.-L. Pan, V. Koren, Q. Y. Duan, M. Ek and A. Betts (1996). Modeling of land surface evaporation by four schemes and comparison with FIFE observations. Journal of Geophysical Research. D. Atmospheres 101: 7251-7268.

Disseldorp, D. A., Monerris, A., Walker, J.P., Yee,M. (2013). Development of a validation site in Australia for the SMAP mission using temporal stability anlaysis, Monash University, Clayton, Australia.

EORC (2013). Status of AMSR2 Level-2 Products (Algorithm Version. 1.00), Japan Aerospace Research Centre and GCOM-W1 Algoritm Development PI.

Grasselt, R., D. Schuttemeyer, K. Warrach-Sagi, F. Ament and C. Simmer (2008). Validation of TERRA-ML with discharge measurements. Meteorologische Zeitschrift 17(6): 763-773.

Grayson, R. and G. Blösch (2001). Spatial patterns in catchment hydrology: observations and modelling, CUP Archive.

Imaoka, K., M. Kachi, M. Kasahara, N. Ito, K. Nakagawa and T. Oki (2010). Instrument performance and calibration of AMSR-E and AMSR2. International Archives of the Photogrammetry, Remote Sensing and Special Information Science 38(Part 8).

Jackson, T. J. (1993). III. Measuring surface soil moisture using passive microwave remote sensing. Hydrological Processes 7(2): 139-152.

Jones, D. A., W. Wang and R. Fawcett (2009). High-quality spatial climate data-sets for Australia. Australian Meteorological and Oceanographic Journal 58(4): 233.

Li, Z., L. Zhao and Z. Fu (2012). Estimating net radiation flux in the Tibetan Plateau by assimilating MODIS LST products with an ensemble Kalman filter and particle filter. International Journal of Applied Earth Observation and Geoinformation 19(0): 1-11.

Loaiza Usuga, J. C. and V. Pauwels (2008). Calibration and multiple data set-based validation of a land surface model in a mountainous Mediterranean study area. Journal of Hydrology 356(1): 223-233.

Lymburner, L. and G. Australia (2011). The National Dynamic Land Cover Dataset, Geoscience Australia.

McKenzie, N. J., D. Jacquier, L. Ashton and H. Cresswell (2000). Estimation of soil properties using the Atlas of Australian Soils, CSIRO Land and Water Canberra.

Merlin, O., J. Walker, R. Panciera, R. Young, J. Kalma and E. Kim (2007). Soil moisture measurement in heterogeneous terrain. Proc. Int. Congr. MODSIM: 10-13.

Merlin, O., J. P. Walker, J. D. Kalma, E. J. Kim, J. Hacker, R. Panciera, R. Young, G. Summerell, J. Hornbuckle and M. Hafeez (2008). The NAFE'06 data set: Towards soil moisture retrieval at intermediate resolution. Advances in Water Resources 31(11): 1444-1455.

Panciera, R., J. P. Walker, T. J. Jackson, D. A. Gray, M. A. Tanase, D. Ryu, A. Monerris, H. Yardley, x000Fc, C. diger, N. Wu, Y. Gao and J. M. Hacker (2013). The Soil Moisture Active Passive Experiments (SMAPEx): Toward Soil Moisture Retrieval From the SMAP Mission. Geoscience and Remote Sensing, IEEE Transactions on PP(99): 1-18.

Panciera, R., J. P. Walker, J. Kalma and E. Kim (2011). A proposed extension to the soil moisture and ocean salinity level 2 algorithm for mixed forest and moderate vegetation pixels. Remote Sensing of Environment.

Peischl, S., J. Walker, C. Rüdiger, N. Ye, Y. Kerr, E. Kim, R. Bandara and M. Allahmoradi (2012). The AACES field experiments: SMOS calibration and validation across the Murrumbidgee River catchment. Hydrology and Earth System Sciences Discussions 9(3): 2763-2795.

Rasmy, M. (2013). Development of Soil RTM incorporating Soil Profile Information. The University of Tokyo.

Raupach, M., P. Briggs, V. Haverd, E. King, M. Paget and C. Trudinger. (2012). Australian Water Availability Project. Retrieved 20/06/2013, 2013, from http://csiro.au/awap.

Raupach, M. R., P. Briggs, V. Haverd, E. King, M. Paget and C. Trudinger (2009). Australian water availability project (AWAP): CSIRO marine and atmospheric research component: final report for phase 3, Bureau of Meteorology and CSIRO.

Refsgaard, J. C. (1997). Parameterisation, calibration and validation of distributed hydrological models. Journal of Hydrology 198(1-4): 69-97.

Shahrban, M., J. Walker, Q. Wang, A. Seed, P. Steinle, F. Chan, D. Marinova and R. Anderssen (2011). Comparison of weather radar, numerical weather prediction and gauge-based rainfall estimates.

Smith, A., J. Walker, A. Western, R. Young, K. Ellett, R. Pipunic, R. Grayson, L. Siriwardena, F. Chiew and H. Richter (2012). The Murrumbidgee soil moisture monitoring network data set. Water Resources Research 48(7): W07701. 